\title{
Evolving Brain Functional Abnormalities in PSEN1 Mutation Carriers: A Resting and Visual Encoding fMRI Study
}

\author{
Roser Sala-Llonch ${ }^{\mathrm{a}, \mathrm{b}}$, Juan Fortea ${ }^{\mathrm{c}, \mathrm{d}}$, David Bartrés-Faz ${ }^{\mathrm{a}, \mathrm{b}}$, Beatriz Bosch $^{\mathrm{b}, \mathrm{c}}$, Albert Lladó ${ }^{\mathrm{b}, \mathrm{c}}$, \\ Cleofé Peña-Gómez ${ }^{\mathrm{a}}$, Anna Antonell ${ }^{\mathrm{b}, \mathrm{c}}$, Fernando Castellanos-Pinedo ${ }^{\mathrm{e}}$, Nuria Bargalló ${ }^{\mathrm{b}, \mathrm{f}}$, \\ José Luis Molinuevo ${ }^{\mathrm{b}, \mathrm{c}}$ and Raquel Sánchez-Valle ${ }^{\mathrm{b}, \mathrm{c}, *}$ \\ ${ }^{\mathrm{a}}$ Department of Psychiatry and Clinical Psychobiology, Universitat de Barcelona, Barcelona, Spain \\ b Institut d'Investigació Biomèdica August Pi i Sunyer (IDIBAPS), Barcelona, Spain \\ 'Alzheimer's Disease and Other Cognitive Disorders Unit, Department of Neurology, Hospital Clínic, \\ Barcelona, Spain \\ ${ }^{\mathrm{d}}$ Memory Unit, Department of Neurology, Hospital de Sant Pau, Barcelona, Spain \\ ${ }^{\mathrm{e}}$ Department of Neurology, Hospital Virgen del Puerto, Plasencia, Spain \\ ${ }_{\mathrm{f}}^{\mathrm{f}}$ Department of Radiology, Hospital Clínic, Barcelona, Spain
}

Accepted 11 March 2013

\begin{abstract}
PSEN1 mutations are the most frequent cause of familial Alzheimer's disease and show nearly full penetrance. Here we studied alterations in brain function in a cohort of 19 PSEN1 mutation carriers: 8 symptomatic (SMC) and 11 asymptomatic (AMC). Asymptomatic carriers were, on average, 12 years younger than the predicted age of disease onset. Thirteen healthy subjects were used as a control group (CTR). Subjects underwent a 10-min resting-state functional magnetic resonance imaging (fMRI) scan and also performed a visual encoding task. The analysis of resting-state fMRI data revealed alterations in the default mode network, with increased frontal connectivity and reduced posterior connectivity in AMC and decreased frontal and increased posterior connectivity in SMC. During task-related fMRI, SMC showed reduced activity in regions of the left occipital and left prefrontal cortices, while both AMC and SMC showed increased activity in a region within the precuneus/posterior cingulate, all as compared to CTR. Our findings suggest that fMRI can detect evolving changes in brain mechanisms in PSEN1 mutation carriers and support the use of this technique as a biomarker in Alzheimer's disease, even before the appearance of clinical symptoms.
\end{abstract}

Keywords: Alzheimer's disease, default mode network, functional magnetic resonance imaging, presenilin1, visual memory

\section{INTRODUCTION}

A minority of Alzheimer's disease (AD) cases is inherited with an autosomal dominant pattern of inheritance [1] and is caused by a genetic mutation. The mutations identified so far (http://www.molgen. ua.ac.be) affect the amyloid- $\beta$ protein precursor,

\footnotetext{
*Correspondence to: Raquel Sánchez-Valle, Alzheimer's Disease and Other Cognitive Disorders Unit, Department of Neurology, Hospital Clínic, Villarroel 170, 08036 Barcelona, Spain. Tel.: +34 932275785; Fax: +34 932275783; E-mail: rsanchez@clinic.ub.es.
}

presenilin-1 (PSEN1), and presenilin-2. These forms, also called familial $\mathrm{AD}$, show almost $100 \%$ penetrance and have an early age of onset, which is also relatively predictable in a given family [2]. They are a good model that allows us to look into the early pathogenic mechanisms of the disease [3].

Altered synaptic function is characteristic of $\mathrm{AD}$ and there is consistent evidence that it is present very early in the disease process, possibly long before the development of clinical symptoms or even of significant neuropathology [4]. Functional magnetic 
resonance imaging (fMRI) is based on the strength of the blood-oxygen-level-dependent (BOLD) signal and it is thought to provide an in vivo correlate of neural activity. Thus, it is particularly useful for detecting alterations in brain function that may be present very early in the course of $\mathrm{AD}$ [5]. When examined at rest, fMRI can be used to study patterns of intrinsic brain connectivity or functional networks [6]. The most widely studied of these patterns is the default mode network (DMN), which involves the precuneus and posterior cingulate cortex, parietal and temporal cortices bilaterally, and the medial prefrontal cortex, as well as some regions within the hippocampal memory system [7, 8]. DMN regions are typically co-activated during rest and deactivated during the processing of external stimuli, and they are among the earliest and most consistently affected regions in $\mathrm{AD}$ [9]. DMN functioning and connectivity have been widely assessed along the $\mathrm{AD}$ continuum, with functional connectivity abnormalities being reported in both AD [10-14] and mild cognitive impairment [15-17]. Furthermore, studies with cognitively-preserved populations at risk for $\mathrm{AD}$ have shown abnormal connectivity in elderly subjects with evidence of amyloid deposition [18-21], as well as in in apolipoprotein (APOE) $\varepsilon 4$ carriers [22-26]. However, to the best of our knowledge, there are no published studies assessing the effect of the presence of a pathogenic PSEN1 mutation on the DMN.

Another fMRI strategy, known as task-related fMRI, can be used to study brain activity when the subject is engaged in a given task. By using memory encoding paradigms, fMRI studies have revealed taskassociated brain activity during encoding in a specific set of brain regions that include the medial temporal lobe, prefrontal cortex, and ventral temporal cortex [5]. During the encoding of new information, patients with AD have shown decreased fMRI activation in the hippocampus and related structures within the medial temporal lobe when compared to their matched control subjects [27]. However, it has been suggested that there may be a phase of paradoxically increased activation earlier in the course of the disease, that is, in prodromal $\mathrm{AD}$ or in individuals at genetic risk for $\mathrm{AD}[28,29]$.

Few encoding-based fMRI studies have been conducted in PSEN1 mutation carriers. Encoding-related activity was found to be altered in one asymptomatic mutation carrier (AMC) subject 30 years prior to the mean familial age of onset [30]. In other studies, PSEN1 AMC exhibited increased activation in the right hippocampus and parahippocampus during memory encoding [31]. Increased fMRI activity was also reported in the fusiform and middle temporal gyri as mutation carriers approached the mean familial age of disease diagnosis [32].

Based on previous work, we hypothesized that PSEN1 mutation carriers would demonstrate functional connectivity changes in the DMN along disease progression. We further hypothesized that during visual memory fMRI, symptomatic mutation carriers (SMC) would present a pattern of reduced brain activity similar to what is reported in sporadic $\mathrm{AD}$, and also that task-related activity within memory networks would already be altered in AMC compared to normal controls. In order to test these hypotheses, we examined brain functioning in a sample of PSEN1 mutation carriers, including both asymptomatic and symptomatic subjects. Specifically, this was done by analyzing the DMN during resting fMRI and memory networks during encoding-based task fMRI.

\section{MATERIALS AND METHODS}

\section{Subjects}

Nineteen mutation carriers from 8 families with 6 different PSEN1 mutations (M139T, K239N, L235R, L282R, L286P, I439S) and 13 normal controls, asymptomatic non-carriers, were recruited from the genetic counseling program for familial dementias (PICOGEN) at the Hospital Clinic, Barcelona, Spain [33]. Subjects were made aware of their at-risk status for genetic $\mathrm{AD}$ in a session of genetic counseling and were given the option of knowing their genetic status through the genetic counseling protocol. The study was approved by the Hospital Clinic ethics committee and all subjects gave written informed consent.

\section{Genetic analysis}

Genomic DNA was extracted from peripheral blood using the QIAamp DNA Blood Mini Kit (Qiagen). Mutation screening was performed as previously described [34].

\section{Clinical and neuropsychological characterization}

Subjects underwent clinical and cognitive assessments, and a comprehensive neuropsychological battery was also administered, as described previously [35]. Subjects were classified clinically as asymptomatic (AMC) if they had no memory complaints, 
a normal cognitive assessment, and a score of 0 on the Clinical Dementia Rating (CDR) scale. They were classified as symptomatic (SMC) if their cognitive performance was more than 1.5 SD below the mean with respect to their age and educational level on any cognitive test and/or if their CDR score was $>0$.

The current sample included 8 families with 6 different mutations and different median ages of onset (range 40-54 years). In order to compare subjects from different families, we therefore defined and calculated for each mutation carrier the adjusted age as the subject's age relative to the median familial age of onset.

\section{MRI scanning}

All subjects were scanned in a 3T machine (Siemens Trio Tim, Siemens, Germany) during both a 10min resting fMRI protocol and while performing a visual encoding task. During scanning, a set of T2*weighted volumes were acquired (voxel size $=1.7 \times$ $1.7 \times 3.0 \mathrm{~mm}, \mathrm{TR}=2000 \mathrm{~ms}, \mathrm{TE}=29 \mathrm{~ms}, 36$ slices per volume, slice thickness $=3 \mathrm{~mm}$, distance factor $=25 \%, \mathrm{FOV}=240 \mathrm{~mm}$, matrix size $=128 \times 128$ ). A high-resolution 3D structural dataset (T1-weighted MP-RAGE, voxel size $=1.0 \times 1.0 \times 1.0 \mathrm{~mm}, \mathrm{TR}=$ $2300 \mathrm{~ms}, \mathrm{TE}=2.98 \mathrm{~ms}, 240$ slices, FOV $=256 \mathrm{~mm}$, matrix size $=256 \times 256$, slice thickness $=1 \mathrm{~mm}$ ) was acquired in the same session.

During resting-state, subjects were asked to lie down in the machine, to not think of anything in particular, and to avoid falling asleep. For encoding-fMRI, we employed a visual encoding task used previously by our group [36]. Briefly, this consisted of a 15block design paradigm with alternating "fixation", "repeated", and "encoding" conditions. During "fixation", a white cross on a black screen was presented to the subject; during the "repeated" condition, a sample image was presented repeatedly to the subject; while during "encoding", a set of new colored images was shown to the subject for each block. The whole session lasted 7 minutes and 30 seconds and subjects were tested for their memory performance outside the scanner in a two-alternative forced-choice task (maximum score of 50).

\section{Preprocessing and analysis of resting-state fMRI data}

Resting-fMRI data were preprocessed using tools implemented in both FSL (http://www.fmrib.ox. ac.uk/fsl/) and AFNI (http://afni.nimh.nih.gov/afni) softwares. The procedures for data preprocessing included: removing the first 5 scans, motion correction [37], skull stripping/removal of non-brain voxels [38], spatial smoothing (using a Gaussian kernel of $\mathrm{FWHM}=6.0 \mathrm{~mm}$ ), grand mean scaling of the whole 4D series, temporal filtering (with a bandpass filter, $0.01-0.1 \mathrm{~Hz}$ ), and removal of linear and quadratic trends. Nuisance variables were regressed out from preprocessed resting-fMRI data. These included the 6 motion parameters, global whole-brain BOLD signal, and white matter and cerebrospinal fluid oscillations. In order to perform group analyses, we registered each individual functional acquisition to Montreal Neurological Institute (MNI) standard space by using a two-step registration with FMRIB's Linear Image Registration Tool (FLIRT; [39]), involving the registration of each individual fMRI set to its anatomical highresolution scan and the registration from anatomical space to the standard MNI template.

Resting-fMRI data were further analyzed using seed-based connectivity. A region of interest (ROI) placed in the precuneus/posterior cingulate (spherical ROI of $6 \mathrm{~mm}$ radius centered at MNI coordinates $\mathrm{x}=2$, $\mathrm{y}=-54, \mathrm{z}=24$; [40]) was used to assess whole-brain resting-state functional connectivity. The procedure for seed-based connectivity was performed on preprocessed resting data as follows: 1) average time-series were extracted for each subject within the ROI; 2) these time-series were then used to calculate the temporal correlation against all the voxels in the brain; and 3 ) individual correlation maps were transformed into Z-scores using Fisher's $r$ to $\mathrm{Z}$ transformation, and then moved to MNI standard space. All Z maps were concatenated and introduced into a voxel-wise group statistical analysis using General Linear Modeling. Group analysis included average connectivity maps for each group (one-sample $t$-test) and group differences (two-sample $t$-test). Results were corrected for multiple comparisons using a permutation-based method with 5000 iterations [41].

\section{Preprocessing and analysis of encoding-fMRI data}

Task-fMRI data were analyzed using a modeldriven approach, as implemented in the FMRI Analysis Tool (FEAT) from FSL. Data preprocessing included motion correction [37], non-brain removal [38], spatial smoothing with a Gaussian kernel of FWHM $6 \mathrm{~mm}$, grand-mean intensity normalization, and highpass temporal filtering $($ sigma $=50.0 \mathrm{~s})$. Time-series statistical analysis was carried out for each piece of 
individual functional data using FMRIB's Improved Linear Model (FILM) with local autocorrelation correction [42]. Three regressors were used to model the different task blocks (encoding, repeated, and fixation), and three additional regressors, modeling their first derivatives, were introduced as nuisance variables. Individual activation maps were computed from the preprocessed functional data using the "encoding" > "repeated" images contrast.

In order to assess group-activation maps and group differences, we performed higher-level analyses using the General Linear Model and FLAME (FMRIB's Local Analysis of Mixed Effects) stage 1 and stage 2 [43-45]. This included averaged maps for the three groups (CTR, AMC, and SMC) and group comparisons (CTR versus AMC and CTR versus SMC). Performance scores, measured as the number of correctly recognized images, were introduced as covariates for the group comparisons.

Two additional correlation analyses were performed using encoding-fMRI data. First, and in order to assess brain activity associated with correct coding of new images, we created a General Linear Model design in which whole-brain activity maps were regressed against individual performance scores for the three groups separately. Then, and based on the results reported by Braskie et al. [32], who found increased functional activity as their subjects approached the age of onset, we evaluated the relationship between brain activation maps and adjusted age in the AMC subgroup.

\section{Statistical analysis}

Group analyses were conducted using PASW (Predictive Analytics SoftWare, IBM Corp.) v.18. Comparisons between groups were performed using the two-tailed Student's $t$ test or ANOVA for continuous variables, and a chi square test for categorical variables.

\section{RESULTS}

Demographics, cognitive testing and genetic status

Demographic and clinical data of the participants are summarized in Table 1. Eight mutation carriers were $\mathrm{SMC}$, with a mean age of 48.91 years $(\mathrm{SD}=7.53)$. The remaining 11 mutation carriers were AMC, with a mean age of 39.09 years $(S D=10.74)$ and a mean adjusted age of -11.92 years $(\mathrm{SD}=8.96)$. There were 13 controls (36.27 years \pm 7.45$)$. Age and Mini-Mental State Examination (MMSE) scores did not differ between controls and AMC (Table 1). As expected, SMC were older than both controls and AMC, and they presented significantly different MMSE scores.

\section{Resting-state connectivity}

\section{Average default mode network maps}

The seed-based connectivity analysis of restingstate fMRI data from the precuneus/posterior cingulate ROI (ROI placement is shown in Fig. 1A) identified a pattern of connectivity that corresponded to the DMN in each group separately (Fig. 1B-D). The DMN maps included areas in bilateral parietal regions and both angular gyri (for the three groups), as well as areas in the medial prefrontal cortex (only in the control and AMC groups).

\section{Group differences}

Figures 1E-H show the results of voxel-wise group comparisons of the precuneus/posterior cingulate connectivity maps. When compared to the control group, AMC showed reduced resting-state connectivity in areas of the hippocampus, parahippocampal, lingual and fusiform gyri, the middle temporal cortex and parts of the precuneus/posterior cingulate, and the lateral occipital cortex. Conversely, AMC presented increased connectivity in the paracingulate and anterior cingulate, parts of the superior, middle and inferior frontal cortices, and in the frontal pole.

Table 1

Demographic and clinical data in the different groups. ${ }^{*} p<0.05$ compared to controls

\begin{tabular}{lccc}
\hline & $\begin{array}{c}\text { Healthy controls (non-carriers) } \\
(n=13)\end{array}$ & $\begin{array}{c}\text { Asymptomatic mutation carriers } \\
(n=11)\end{array}$ & $\begin{array}{c}\text { Symptomatic mutation carriers } \\
(n=8)\end{array}$ \\
\hline Age (years) & $36.27(7.45)$ & $39.09(10.74)$ & $48.91(7.53)^{*}$ \\
Relative age (years) & NA & $-11.92(8.96)$ & $3.35(2.94)$ \\
Education (years) & $14(3.91)$ & $12.45(2.54)$ & $10.88(3.09)$ \\
Gender (\%Female) & $53.84 \%$ & $63.63 \%$ & $62.50 \%$ \\
MMSE & $29.54(0.50)$ & $29.09(1.04)$ & $19.63(6.21)^{*}$ \\
CDR-total & 0 & 0 & $1.25(0.65)^{*}$ \\
\hline
\end{tabular}

MMSE, Mini-Mental State Examination; CDR, Clinical Dementia Rating. 
A. PCC seed

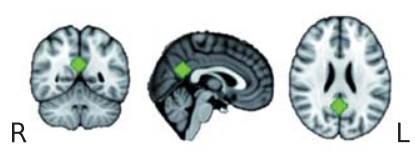

B. CTR - average

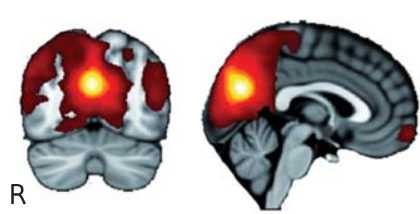

C. AMC - average
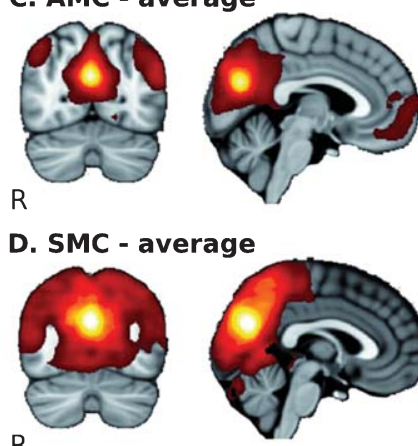
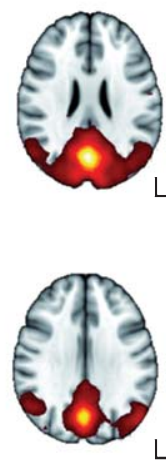

$\mathrm{R}$

E. CTR > AMC
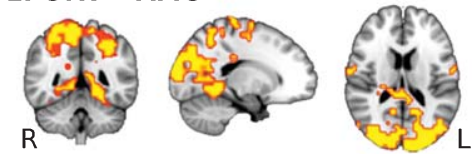

F. AMC > CTR
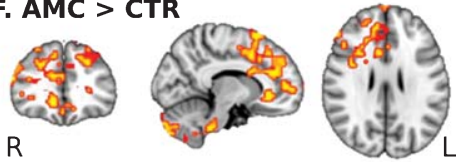

G. CTR > SMC
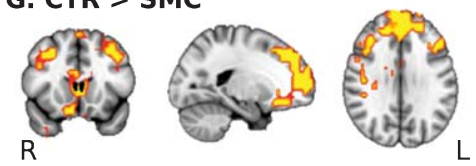

H. SMC > CTR
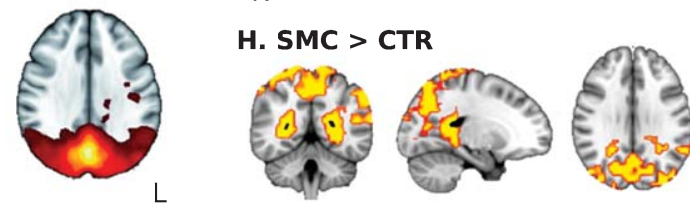

corrected $p$

Fig. 1. Seed-based connectivity analysis of resting-state fMRI data. A) Location of the posterior cingulate cortex (PCC) seed in MNI standard space (spherical ROI of $6 \mathrm{~mm}$ radius; MNI coordinates $\mathrm{x}=2, \mathrm{y}=-54, \mathrm{z}=24)$. B) Average connectivity maps for healthy controls (CTR). C) Average connectivity map for asymptomatic mutation carriers (AMC). D) Average connectivity map for symptomatic mutation carriers (SMC). E-H) Group difference maps corrected for multiple comparisons. All difference maps are thresholded at a corrected family-wise $p<0.05$ level. Maps $(\mathrm{G})$ and $(\mathrm{H})$ include age as a covariate.

The SMC group showed reduced connectivity with respect to controls in the anterior cingulate and paracingulate, the frontal pole, the medial frontal cortex, and the superior frontal gyrus. However, SMC had increased connectivity in supramarginal areas, the angular gyrus, parietal cortex, precuneus cortex, supracalcarine cortex, and lingual/fusiform areas. These results remain significant when age was included as covariate.

\section{Encoding-fMRI activity}

fMRI data during encoding were available for a subsample of 23 subjects (12 controls, 6 AMC, and 5 SMC subjects). This sample size difference was due to timing limitations during the scanning session, to excessive movement and MRI-related artifacts, and to extremely poor task performance.

\section{Task performance outside the scanner}

Memory performance outside the scanner did not differ significantly between AMC and control subjects. However, there was a trend for AMC subjects to perform worse than controls [mean (SD) values were 47.54 (2.21) for controls versus 40.84 (7.94) for AMC; $t=2.14, p=0.08]$. SMC had a poorer performance outside the scanner (mean: 23.0, SD: 16.32) than both controls $(t=3.35, p=0.028)$ and AMC $(t=2.4$, $p=0.039$ ).

\section{Average maps}

All group-average maps revealed the main pattern of brain regions involved in encoding for novel images ("encoding" > "repeated" condition). For the control and AMC groups (Fig. 2A and B, respectively), activity patterns included the lateral occipital cortex (left and right), the temporal occipital fusiform cortex, the middle and inferior temporal gyrus, the lingual gyrus, and the parahippocampal gyrus. Moreover, in the control group we also observed activity in the middle and inferior frontal gyrus bilaterally (although more pronounced in the left hemisphere), as well as in the frontal medial cortex and paracingulate gyrus (Fig. 2A). The group-average maps for the SMC group revealed areas of activity in the lateral occipital cortex, middle temporal gyrus, lingual gyrus, angular gyrus, and fusiform (Fig. 2C), although to a lesser extent than in controls and AMC. There was no activity in frontal areas in SMC. 

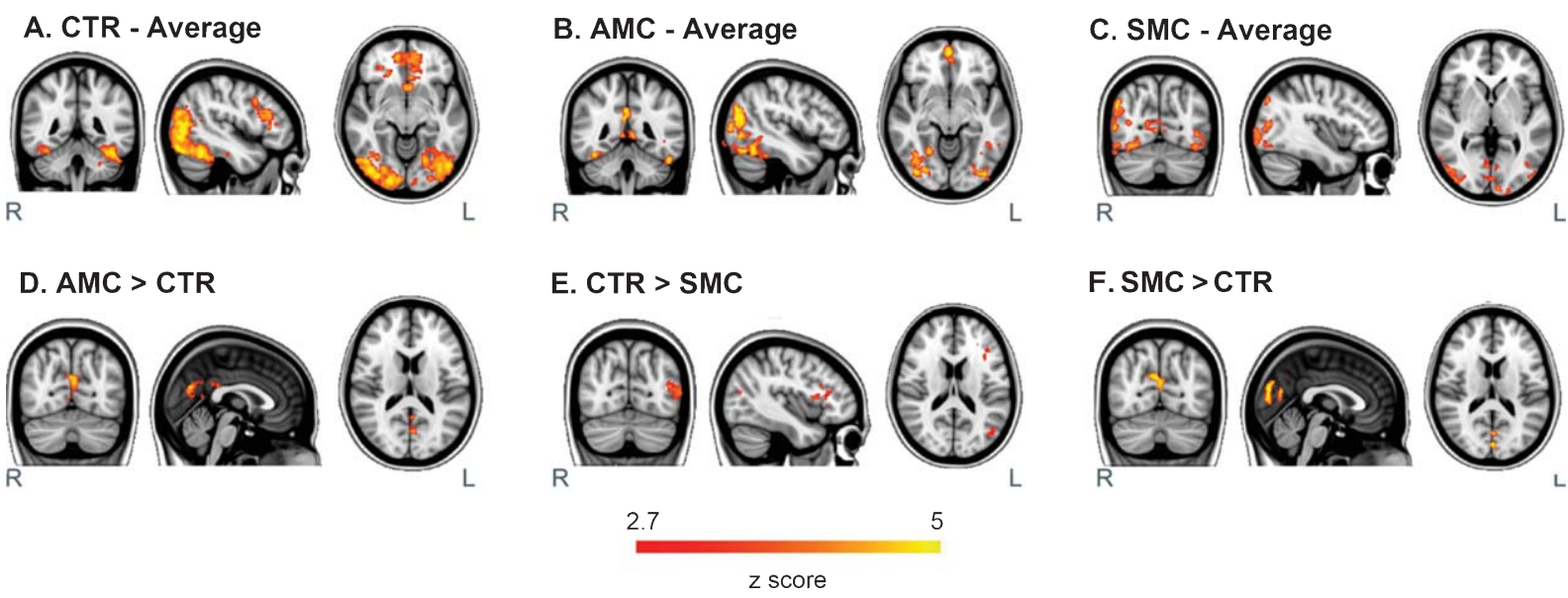

Fig. 2. Results of the analysis of task-related fMRI activity in the "encoding > repeated" images condition. A) Average map for the healthy control (CTR) group. B) Average map for the asymptomatic mutation carrier (AMC) group. C) Average map for the symptomatic mutation carrier (SMC) group. D) Areas where AMC had greater task-associated BOLD response than did CTR. E) Areas where SMC showed less task-associated BOLD response than did CTR. F) Areas where SMC had greater task-associated BOLD response with respect to CTR. Maps (E) and (F) include age as a covariate.

Table 2

Group differences in brain activity during memory encoding. Summary of significant clusters in the "encoding > repeated" images contrast

\begin{tabular}{|c|c|c|c|c|c|c|}
\hline \multirow[t]{2}{*}{ Cluster } & \multirow[t]{2}{*}{ Size $\left(\mathrm{mm}^{2}\right)$} & \multirow[t]{2}{*}{ Cluster $\mathrm{p}$} & \multirow[t]{2}{*}{$\mathrm{Z} \max$} & \multicolumn{3}{|c|}{ Peak coordinates $(\mathrm{MNI})$} \\
\hline & & & & $\mathrm{x}$ & $\mathrm{y}$ & $\mathrm{z}$ \\
\hline \multicolumn{7}{|c|}{ Asymptomatic Mutation Carriers $>$ Controls } \\
\hline 1 & 1952 & 0.000253 & 4.96 & 2 & -68 & 24 \\
\hline \multicolumn{7}{|c|}{ Symptomatic Mutation Carriers $>$ Controls } \\
\hline 1 & 1276 & 0.0171 & 4.05 & 0 & -84 & 28 \\
\hline \multicolumn{7}{|c|}{ Controls $>$ Symptomatic Mutation Carriers } \\
\hline 1 & 1160 & 0.015 & 4.33 & -38 & 16 & 12 \\
\hline 2 & 1220 & 0.0109 & 4.89 & -54 & -74 & 8 \\
\hline
\end{tabular}

\section{Group comparisons}

In the "encoding > repeated" images contrast, AMC showed increased BOLD activity in comparison with the control group in regions of the precuneus/posterior cingulate cortex (Fig. 2D). There were no regions of increased BOLD activity in the control group with respect to AMC. SMC showed decreased BOLD activity with respect to controls in a region within the left middle and inferior frontal gyri and left frontal operculum, as well as in the left lateral occipital cortex (Fig. 2E). Conversely, SMC showed areas of increased BOLD activity in comparison with controls in the precuneus cortex, the intracalcarine cortex, and in part of the lingual gyrus (Fig. 2F). The results of all these comparisons are also summarized in Table 2.

\section{Correlations with task performance}

Brain activity was positively correlated with performance outside the scanner in the AMC group. This positive association involved areas of the right parahippocampal gyrus, right hippocampus, and right temporal fusiform and lingual gyrus (Fig. 3A). We extracted average signal change between repeated and encoding conditions for each individual within these regions (Fig. 3A, right panel). Task performance correlated with activity scores in AMC $(r=0.98, p<0.001)$ but not in the control group ( $r=0.27, p=0.42$ ).

\section{Correlations with adjusted age}

In AMC, BOLD activity during encoding was positively correlated with the adjusted age of subjects in regions within the angular gyrus $(r=0.94, p=0.005$; Fig. 3B). In other words, subjects who were closer to their familial age of onset showed greater activation in these areas.

\section{DISCUSSION}

We performed an fMRI study to assess resting-state and encoding-task activity in a cohort of symptomatic 
A

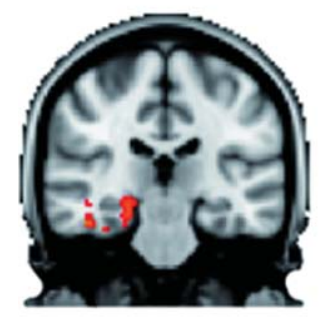

$\mathrm{R}$

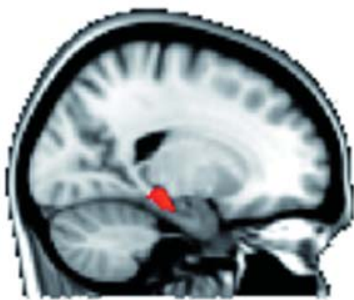

2.7

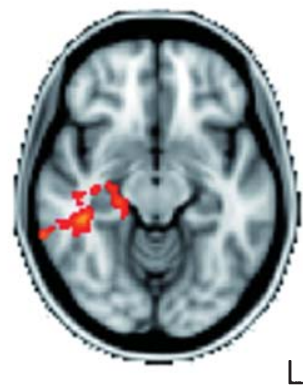

$\mathrm{L}$

B

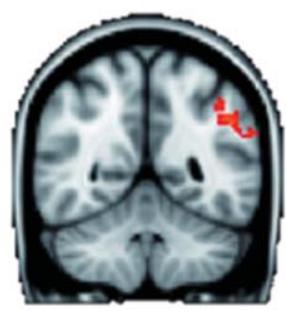

R

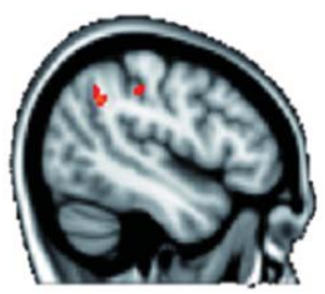

2.7

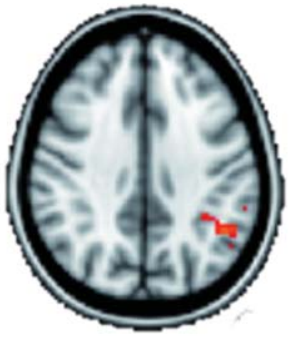

L
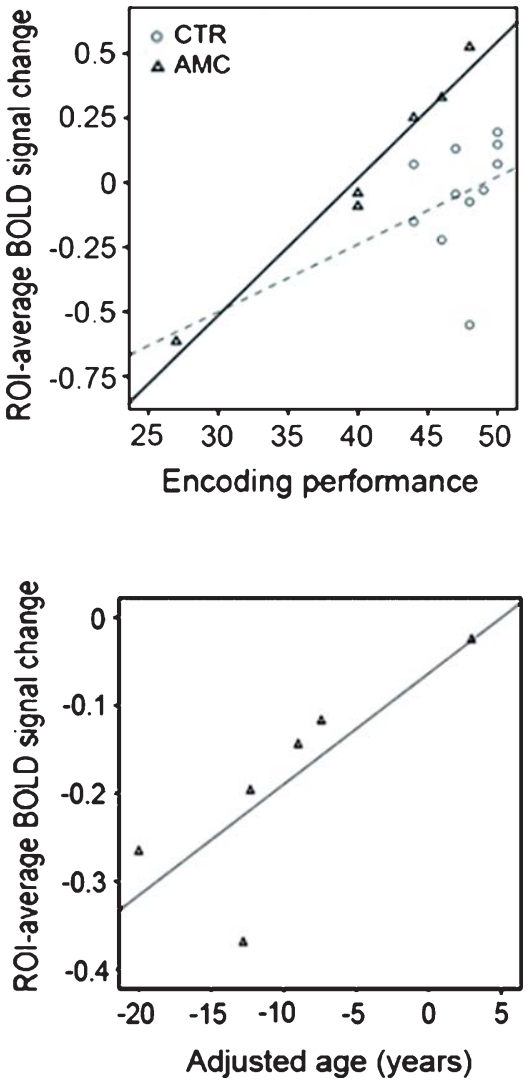

Fig. 3. Correlations found with encoding-related brain activity in the asymptomatic mutation carrier (AMC) group. A) Correlations with task performance. Spatial map of brain regions with significant correlation (left panel) and scatter plot of performance scores and mean BOLD signal change within significant areas in AMC subjects and healthy controls (CTR) (right panel). B) Correlations with adjusted age within AMC subjects. Spatial map of brain regions showing significant correlation (left panel) and scatter plot of adjusted age and mean BOLD signal change in these regions (right panel). All maps are thresholded at a corrected level of $p<0.05$.

and asymptomatic PSEN1 mutation carriers and a group of matched healthy controls. To the best of our knowledge, this is the first study to examine intrinsic functional connectivity by means of restingstate fMRI in PSEN1 subjects. The asymptomatic and symptomatic subjects showed divergent changes in connectivity between the anterior and posterior components of the DMN, with connectivity being increased in AMC and reduced in SMC. Conversely, short distance connections in posterior regions of the DMN were increased in SMC and decreased in AMC. The analysis of task fMRI revealed common encoding-related BOLD activity in areas within the memory network. Compared to controls, SMC showed reduced activity in left prefrontal and left occipital cortices. However, both SMC and AMC presented increased activity during encoding compared to controls in areas of the precuneus/posterior cingulate.

The reduced connectivity from the precuneus/ posterior cingulate to frontal areas in SMC is consis- tent with previous studies that have assessed the DMN in sporadic $\mathrm{AD}$ and mild cognitive impairment [10, $12,15]$. Moreover, the increased within-lobe functional connectivity in the same subjects is also in line with previously published research on sporadic AD [11,46] and mild cognitive impairment [15]. However, other studies on AD have also showed opposite changes with decreases in functional connectivity of posterior regions and increases in frontal regions (reviewed in [47]). These discrepancies may rely on differences in the methodology used to isolate the DMN together with differences in subjects' atrophy between studies.

More interesting, we also found altered connectivity in mutation carriers prior to the appearance of clinical symptoms. Specifically, AMC subjects showed reduced resting-state connectivity from the precuneus/posterior cingulate to other posterior brain regions, including part of the hippocampus, the fusiform and parahippocampal gyri, and the lingual gyrus. These regions are known to be structurally 
affected very early in AD and this reduction in connectivity is in accordance with seed-based studies that have demonstrated decreased connectivity in $\mathrm{AD}$ between the hippocampus and DMN regions [48]. We also found an increase in precuneus/posterior cingulate functional connectivity within frontal regions. We suggest two explanations for the increased connectivity between the posterior and anterior core components of the DMN in AMC. First, the increased functional connectivity in the frontal cortex might reflect reorganization mechanisms within the network that serve to maintain function despite the reduced connectivity with medial temporal and hippocampal regions of the DMN found in AMC. These increases in frontal areas agree with studies identifying the frontal lobe as a key region for functional compensation mechanisms in $\mathrm{AD}$ [49]. On the other hand, the increased functional connectivity might also reflect aberrant excitatory responses to early amyloid- $\beta$ deposition that could trigger a variety of inhibitory compensatory responses in memory circuits and would, thus, explain the divergent network connectivity changes in the medial temporal lobe and prefrontal regions [4, 29, 50]. Our results are congruent with the findings in APOE $\varepsilon 4$ carriers [51, 52] with increased connectivity in frontal regions of the DMN.

During visual encoding, SMC showed reduced activity in encoding-associated areas such as the left occipital and left prefrontal cortex. The results in SMC confirm the decreased brain activity engaged by the visual memory task that has been widely reported in the literature on sporadic AD [27]. AMC showed increased encoding-related BOLD activity in precuneus/posterior cingulate with respect to controls. These results are in agreement with studies of preclinical AD by our group [36] and others [19, 29] and have been interpreted as a compensatory mechanism, as the precuneus/posterior cingulate plays an important role in memory functions. In healthy young controls, precuneus/posterior cingulate deactivates during encoding and is activated in retrieval, a phenomenon known as the encoding/retrieval flip. Impaired ability to modulate activity in the precuneus/posterior cingulate has been associated with increasing age, greater amyloid burden, and worse memory performance [53] and has also been described in healthy APOE $\varepsilon 4$ carriers [54-57], and in a previous study in another sample of PSEN1 asymptomatic carriers [58]. The hyperactivity (or lack of deactivation) in the precuneus/posterior cingulate could be a consequence of amyloid deposition, that would produce a decrease in synaptic inhibition and modify the functional properties of the neurons themselves, rendering them hyperactive [59] or a compensatory mechanism, in the sense that additional cognitive resources are required to achieve and maintain a performance level similar to that of noncarriers. In the same sense, a previous study of PSEN1 mutation carriers showed that fMRI activity in the fusiform and middle temporal gyri increased as subjects approached the age of symptom onset, suggesting that during novelty encoding, increased fMRI activity may relate to incipient AD processes [32, 60].

Of note, we also found a significant correlation both between brain activity and performance outside the scanner and between brain activity and adjusted age in the AMC group. First, activity in areas in the right middle temporal and right hippocampus correlated with task performance, indicating that the system might be already compromised prior to the appearance of symptoms. In the same sense, positive correlations between hippocampus activity and encoding performance have previously been reported in PSEN1 mutation carriers $[30,31]$. The positive correlation between adjusted age and brain activity in a region within the left angular gyrus is in agreement with the study published by the group of Braskie et al. also based on a visual encoding task [61]. These results, together with the previously discussed hyperactivity in the precuneus/posterior cingulate, suggest that the activity of other regions such as the hippocampus or the angular gyrus would compensate in PSEN1 mutation carriers a precocious alteration in the encoding/retrieval flip.

Thus, taken together, our results would support the possibility of a phase of paradoxically increased activation early in the course of the disease that evolves over the course of the AD disease process [5, 28]. The present study therefore provides evidence to support that fMRI may be a suitable biomarker in familial $\mathrm{AD}$ to track longitudinally disease progression. In contrast, the distinct and evolving changes in the DMN in PSEN1, with increases followed by decreases in functional connectivity in some areas, might complicate the interpretation of cross-sectional results.

The main limitation of our study is the relatively small sample size. However, previous investigations in familial AD neuroimaging all have similar sample sizes and the main results survived a correction for multiple comparisons.

In summary, PSEN1 mutation carriers present disruption of normal connections in large-scale networks over a decade before symptoms onset. However, the trajectory of changes during the $\mathrm{AD}$ disease process may be complex, with increases and decreases in functional connectivity in different areas of the memory 
systems and the DMN. These changes might reflect aberrant excitatory responses to amyloid- $\beta$ and subsequent inhibitory responses or functional network reorganization mechanisms that evolve with disease progression.

\section{ACKNOWLEDGMENTS}

This work was supported by research grants from the Instituto Carlos III (FIS080036 and FIS1200013 to RSV) and from the Spanish Ministerio de Ciencia e Innovación (SAF200907489 to DB and BES-2011047053 to RSLL). Juan Fortea was a receptor of a Josep Font grant from Hospital Clinic.

We thank all the volunteers for their participation in this study.

Authors' disclosures available online (http://www.jalz.com/disclosures/view.php?id=1710).

\section{REFERENCES}

[1] Lleo A, Blesa R, Queralt R, Ezquerra M, Molinuevo JL, PenaCasanova J, Rojo A, Oliva R (2002) Frequency of mutations in the presenilin and amyloid precursor protein genes in earlyonset Alzheimer disease in Spain. Arch Neurol 59, 1759-1763.

[2] Fox NC, Kennedy AM, Harvey RJ, Lantos PL, Roques PK, Collinge J, Hardy J, Hutton M, Stevens JM, Warrington EK, Rossor MN (1997) Clinicopathological features of familial Alzheimer's disease associated with the M139V mutation in the presenilin 1 gene. Pedigree but not mutation specific age at onset provides evidence for a further genetic factor. Brain 120, 491-501.

[3] Bateman RJ, Xiong C, Benzinger TL, Fagan AM, Goate A, Fox NC, Marcus DS, Cairns NJ, Xie X, Blazey TM, Holtzman DM, Santacruz A, Buckles V, Oliver A, Moulder K, Aisen PS, Ghetti B, Klunk WE, McDade E, Martins RN, Masters CL, Mayeux R, Ringman JM, Rossor MN, Schofield PR, Sperling RA, Salloway S, Morris JC (2012) Dominantly Inherited Alzheimer Network. Clinical and biomarker changes in dominantly inherited Alzheimer's disease. N Engl J Med 367, 795-804.

[4] Selkoe DJ (2002) Alzheimer's disease is a synaptic failure. Science 298, 789-791.

[5] Dickerson BC, Sperling RA (2009) Large-scale functional brain network abnormalities in Alzheimer's disease: Insights from functional neuroimaging. Behav Neurol 21, 63-75.

[6] Smith SM, Fox PT, Miller KL, Glahn DC, Fox PM, Mackay CE, Filippini N, Watkins KE, Toro R, Laird AR, Beckmann CF (2009) Correspondence of the brain's functional architecture during activation and rest. Proc Natl Acad Sci U S A $\mathbf{1 0 6}$ 13040-13045.

[7] Raichle ME, MacLeod AM, Snyder AZ, Powers WJ, Gusnard DA, Shulman GL (2001) A default mode of brain function. Proc Natl Acad Sci U S A 98, 676-682.

[8] Buckner RL, Andrews-Hanna JR, Schacter DL (2008) The brain's default network: Anatomy, function, and relevance to disease. Ann N Y Acad Sci 1124, 1-38.
[9] Buckner RL, Snyder AZ, Shannon BJ, LaRossa G, Sachs R, Fotenos AF, Sheline YI, Klunk WE, Mathis CA, Morris JC, Mintun MA (2005) Molecular, structural, and functional characterization of Alzheimer's disease: Evidence for a relationship between default activity, amyloid, and memory. $J$ Neurosci 25, 7709-7717.

[10] Greicius MD, Srivastava G, Reiss AL, Menon V (2004) Default-mode network activity distinguishes Alzheimer's disease from healthy aging: Evidence from functional MRI. Proc Natl Acad Sci U S A 101, 4637-4642.

[11] Wang K, Liang M, Wang L, Tian L, Zhang X, Li K, Jiang T (2007) Altered functional connectivity in early Alzheimer's disease: A resting-state fMRI study. Hum Brain Mapp 28, 967-978.

[12] Zhang HY, Wang SJ, Xing J, Liu B, Ma ZL, Yang M, Zhang ZJ, Teng GJ (2009) Detection of PCC functional connectivity characteristics in resting-state fMRI in mild Alzheimer's disease. Behav Brain Res 197, 103-108.

[13] Zhang HY, Wang SJ, Liu B, Ma ZL, Yang M, Zhang ZJ, Teng GJ (2010) Resting brain connectivity: Changes during the progress of Alzheimer disease. Radiology 256, 598-606.

[14] Damoiseaux JS, Prater KE, Miller BL, Greicius MD (2012) Functional connectivity tracks clinical deterioration in Alzheimer's disease. Neurobiol Aging 33, 828.e19-e30.

[15] Sorg C, Riedl V, Muhlau M, Calhoun VD, Eichele T, Laer L, Drzezga A, Forstl H, Kurz A, Zimmer C, Wohlschlager AM (2007) Selective changes of resting-state networks in individuals at risk for Alzheimer's disease. Proc Natl Acad Sci U S A 104, 18760-18765.

[16] Bai F, Watson DR, Yu H, Shi Y, Yuan Y, Zhang Z (2009) Abnormal resting-state functional connectivity of posterior cingulate cortex in amnestic type mild cognitive impairment. Brain Res 1302, 167-174.

[17] Qi Z, Wu X, Wang Z, Zhang N, Dong H, Yao L, Li K (2010) Impairment and compensation coexist in amnestic MCI default mode network. Neuroimage 50, 48-55.

[18] Hedden T, Van Dijk KR, Becker JA, Mehta A, Sperling RA, Johnson KA, Buckner RL (2009) Disruption of functional connectivity in clinically normal older adults harboring amyloid burden. J Neurosci 29, 12686-12694.

[19] Sperling RA, Laviolette PS, O'Keefe K, O'Brien J, Rentz DM, Pihlajamaki M, Marshall G, Hyman BT, Selkoe DJ, Hedden T, Buckner RL, Becker JA, Johnson KA (2009) Amyloid deposition is associated with impaired default network function in older persons without dementia. Neuron 63, 178-188.

[20] Sheline YI, Raichle ME, Snyder AZ, Morris JC, Head D, Wang S, Mintun MA (2010) Amyloid plaques disrupt resting state default mode network connectivity in cognitively normal elderly. Biol Psychiatry 67, 584-587.

[21] Mormino EC, Smiljic A, Hayenga AO, Onami SH, Greicius MD, Rabinovici GD, Janabi M, Baker SL, Yen IV, Madison CM, Miller BL, Jagust WJ (2011) Relationships between beta-amyloid and functional connectivity in different components of the default mode network in aging. Cereb Cortex 21, 2399-2407.

[22] Persson J, Lind J, Larsson A, Ingvar M, Sleegers K, Van Broeckhoven C, Adolfsson R, Nilsson LG, Nyberg L (2008) Altered deactivation in individuals with genetic risk for Alzheimer's disease. Neuropsychologia 46, 1679-1687.

[23] Fleisher AS, Sherzai A, Taylor C, Langbaum JB, Chen K, Buxton RB (2009) Resting-state BOLD networks versus taskassociated functional MRI for distinguishing Alzheimer's disease risk groups. Neuroimage 47, 1678-1690.

[24] Machulda MM, Jones DT, Vemuri P, McDade E, Avula R, Przybelski S, Boeve BF, Knopman DS, Petersen RC, Jack 
CR Jr. (2011) Effect of APOE epsilon4 status on intrinsic network connectivity in cognitively normal elderly subjects. Arch Neurol 68, 1131-1136.

[25] Drzezga A, Becker JA, Van Dijk KR, Sreenivasan A, Talukdar T, Sullivan C, Schultz AP, Sepulcre J, Putcha D, Greve D, Johnson KA, Sperling RA (2011) Neuronal dysfunction and disconnection of cortical hubs in non-demented subjects with elevated amyloid burden. Brain 134, 1635-1646.

[26] Trachtenberg AJ, Filippini N, Ebmeier KP, Smith SM, Karpe F, Mackay CE (2012) The effects of APOE on the functional architecture of the resting brain. Neuroimage 59, 565-572.

[27] Schwindt GC, Black SE (2009) Functional imaging studies of episodic memory in Alzheimer's disease: A quantitative meta-analysis. Neuroimage 45, 181-190.

[28] Sperling R (2007) Functional MRI studies of associative encoding in normal aging, mild cognitive impairment, and Alzheimer's disease. Ann N Y Acad Sci 1097, 146-155.

[29] Mormino EC, Brandel MG, Madison CM, Marks S, Baker SL, Jagust WJ (2012) AB deposition in aging is associated with increases in brain activation during successful memory encoding. Cereb Cortex 22, 1813-1823.

[30] Mondadori CR, Buchmann A, Mustovic H, Schmidt CF, Boesiger P, Nitsch RM, Hock C, Streffer J, Henke K (2006) Enhanced brain activity may precede the diagnosis of Alzheimer's disease by 30 years. Brain 129, 2908-2922.

[31] Quiroz YT, Budson AE, Celone K, Ruiz A, Newmark R, Castrillon G, Lopera F, Stern CE (2010) Hippocampal hyperactivation in presymptomatic familial Alzheimer's disease. Ann Neurol 68, 865-875.

[32] Braskie MN, Medina LD, Rodriguez-Agudelo Y, Geschwind DH, Macias-Islas MA, Cummings JL, Bookheimer SY, Ringman JM (2012) Increased fMRI signal with age in familial Alzheimer's disease mutation carriers. Neurobiol Aging 33, 424.e411-421.

[33] Fortea J, Llado A, Clarimon J, Lleo A, Oliva R, Peri J, Pintor L, Yague J, Blesa R, Molinuevo JL, Sanchez-Valle R (2011) PICOGEN: Five years experience with a genetic counselling program for dementia. Neurologia 26, 143-149.

[34] Sanchez-Valle R, Llado A, Ezquerra M, Rey MJ, Rami L, Molinuevo JL (2007) A novel mutation in the PSEN1 gene (L286P) associated with familial early-onset dementia of Alzheimer type and lobar haematomas. Eur J Neurol 14, 1409-1412.

[35] Fortea J, Sala-Llonch R, Bartres-Faz D, Bosch B, Llado A, Bargallo N, Molinuevo JL, Sanchez-Valle R (2010) Increased cortical thickness and caudate volume precede atrophy in PSEN1 mutation carriers. J Alzheimers Dis 22, 909-922.

[36] Rami L, Sala-Llonch R, Sole-Padulles C, Fortea J, Olives J, Llado A, Pena-Gomez C, Balasa M, Bosch B, Antonell A, Sanchez-Valle R, Bartres-Faz D, Molinuevo JL (2012) Distinct functional activity of the precuneus and posterior cingulate cortex during encoding in the preclinical stage of Alzheimer's disease. J Alzheimers Dis 31, 517-526.

[37] Jenkinson M, Bannister PR, Brady JM, Smith SM (2002) Improved optimisation for the robust and accurate linear registration and motion correction of brain images. NeuroImage 17, 825-841.

[38] Smith SM (2002) Fast robust automated brain extraction. Hum Brain Mapp 17, 143-155.

[39] Jenkinson, Smith SM (2001) A global optimisation method for robust affine registration of brain images. Medi Image Anal 5, 143-156.

[40] Andrews-Hanna JR, Snyder AZ, Vincent JL, Lustig C, Head D, Raichle ME, Buckner RL (2007) Disruption of large-scale brain systems in advanced aging. Neuron 56, 924-935.
[41] Nichols TE, Holmes AP (2002) Nonparametric permutation tests for functional neuroimaging: A primer with examples. Hum Brain Mapp 15, 1-25.

[42] Woolrich MW, Ripley BD, Brady JM, Smith SM (2001) Temporal autocorrelation in univariate linear modelling of FMRI data. Neuroimage 14, 1370-1386.

[43] Beckmann CF, Jenkinson M, Smith SM (2003) Genera multi-level linear modelling for group analysis in FMRI. Neuroimage 20, 1052-1063.

[44] Woolrich MW, Behrens TEJ, Beckmann CF, Jenkinson M, Smith SM (2004) Multi-level linear modelling for FMRI group analysis using Bayesian inference. Neuroimage 21, 1732-1747.

[45] Woolrich M (2008) Robust group analysis using outlier inference. Neuroimage 41, 286-301.

[46] Wang Z, Yan C, Zhao C, Qi Z, Zhou W, Lu J, He Y, Li K (2011) Spatial patterns of intrinsic brain activity in mild cognitive impairment and Alzheimer's disease: A resting-state functional MRI study. Hum Brain Mapp 32, 1720-1740.

[47] Hafkemeijer A, van der Grond J, Rombouts SA (2012) Imaging the default mode network in aging and dementia. Biochim Biophys Acta 1822, 431-441.

[48] Allen G, Barnard H, McColl R, Hester AL, Fields JA, Weiner MF, Ringe WK, Lipton AM, Brooker M, McDonald E, Rubin CD, Cullum CM (2007) Reduced hippocampal functional connectivity in Alzheimer disease. Arch Neurol 64, 14821487.

[49] Prvulovic D, Bokde AL, Faltraco F, Hampel H (2011) Functional magnetic resonance imaging as a dynamic candidate biomarker for Alzheimer's disease. Prog Neurobiol 95, 557569.

[50] Palop JJ, Chin J, Mucke L (2006) A network dysfunction perspective on neurodegenerative diseases. Nature 443, 768773.

[51] Filippini N, MacIntosh BJ, Hough MG, Goodwin GM, Frisoni GB, Smith SM, Matthews PM, Beckmann CF, Mackay CE (2009) Distinct patterns of brain activity in young carriers of the APOE-epsilon4 allele. Proc Natl Acad Sci U S A 106, 7209-7214.

[52] Damoiseaux JS, Seeley WW, Zhou J, Shirer WR, Coppola G, Karydas A, Rosen HJ, Miller BL, Kramer JH, Greicius MD Alzheimer's Disease Neuroimaging Initiative (2012) Gender modulates the APOE $\varepsilon 4$ effect in healthy older adults: Convergent evidence from functional brain connectivity and spinal fluid tau levels. J Neurosci 32, 8254-8262.

[53] Vannini P, Hedden T, Huijbers W, Ward A, Johnson KA, Sperling RA (2012) The ups and downs of the posteromedial cortex: Age- and amyloid-related functional alterations of the encoding/retrieval flip in cognitively normal older adults. Cereb Cortex, doi: 10.1093/cercor/bhs 108

[54] Bartres-Faz D, Serra-Grabulosa JM, Sun FT, Sole-Padulles C, Rami L, Molinuevo JL, Bosch B, Mercader JM, Bargallo N, Falcon C, Vendrell P, Junque C, D'Esposito M (2008) Functional connectivity of the hippocampus in elderly with mild memory dysfunction carrying the APOE epsilon4 allele. Neurobiol Aging 29, 1644-1653.

[55] Bondi MW, Houston WS, Eyler LT, Brown GG (2005) fMRI evidence of compensatory mechanisms in older adults at genetic risk for Alzheimer disease. Neurology 64, 501-508.

[56] Bookheimer SY, Strojwas MH, Cohen MS, Saunders AM, Pericak-Vance MA, Mazziotta JC, Small GW (2000) Patterns of brain activation in people at risk for Alzheimer's disease. $N$ Engl J Med 343, 450-456.

[57] Han SD, Houston WS, Jak AJ, Eyler LT, Nagel BJ, Fleisher AS, Brown GG, Corey-Bloom J, Salmon DP, Thal LJ, Bondi 
MW (2007) Verbal paired-associate learning by APOE genotype in non-demented older adults: fMRI evidence of a right hemispheric compensatory response. Neurobiol Aging 28, 238-247.

[58] Reiman EM, Quiroz YT, Fleisher AS, Chen K, Velez-Pardo C, Jimenez-Del-Rio M, Fagan AM, Shah AR, Alvarez S, Arbelaez A, Giraldo M, Acosta-Baena N, Sperling RA, Dickerson B, Stern CE, Tirado V, Munoz C, Reiman RA, Huentelman MJ, Alexander GE, Langbaum JB, Kosik KS, Tariot PN, Lopera F (2012) Brain imaging and fluid biomarker analysis in young adults at genetic risk for autosomal dominant Alzheimer's disease in the presenilin 1 E280A kindred: A case-control study. Lancet Neurol 11, 1048-1056.

[59] Harris JA, Devidze N, Verret L, Ho K, Halabisky B, Thwin MT, Kim D, Hamto P, Lo I, Yu G-Q, Palop JJ,
Masliah E, Mucke L (2010) Transsynaptic progression of amyloid- $\beta$-induced neuronal dysfunction within the entorhinal-hippocampal network. Neuron 68, 428-441.

[60] Ringman JM, Medina LD, Braskie M, Rodriguez-Agudelo Y, Geschwind DH, Macias-Islas MA, Cummings JL, Bookheimer S (2011) Effects of risk genes on BOLD activation in presymptomatic carriers of familial Alzheimer's disease mutations during a novelty encoding task. Cereb Cortex 21, 877-883.

[61] Braskie MN, Medina LD, Rodriguez-Agudelo Y, Geschwind DH, Macias-Islas MA, Thompson PM, Cummings JL, Bookheimer SY, Ringman JM (2012) Memory performance and fMRI signal in presymptomatic familial Alzheimer's disease. Hum Brain Mapp, doi: 10.1002/hbm.22141 